\title{
Design Optimization Module for Hierarchical Research and Learning Environment
}

\author{
Oktay Baysal, Mehti Koklu, Ahmed K. Noor \\ Aerospace Engineering Department \\ Old Dominion University, Norfolk, VA 23529-0236 \\ E-mail: obaysal@odu.edu
}

\begin{abstract}
The present paper describes a learning module on design optimization courses within a hierarchical research and learning network (HRLN). In this environment a knowledge organization can be created as a hierarchical learning network to link diverse inter- and transdisciplinary teams from a consortium of universities, industry, government agencies and the providers of learning technologies. It is an approach that builds on computer-based training, intelligent tutoring systems, interactive learning, collaborative-distributed learning, and learning networks. The present design optimization module has been developed and described herein, as a demonstrator of a learning module in this environment. This module allows for the learners of design optimization to get the course material at their own convenience and time either via the internet or packaged files. Consequently, it is expected that the learner's ability to understand design optimization and review its pertinent details will be enhanced significantly.
\end{abstract}

\section{On Course Delivery and Pedagogy}

HRLN is configured as a neural network of networks [Refs. 1,2]. Each of the component networks integrates three learning environments: a) synchronous and asynchronous expert-led, b) self-paced, and c) collaborative. The instructional model and method used for this learning network vary from instructor-centered, learner-centered to learning-team-centered. As the name suggests, in the learner-centered model the learner is at the center of the learning process and calls on many information sources. Learning-team-centered models include virtual classrooms and web-based distance learning models. The human instructors in these environments serve many roles, including inspiring, motivating, observing, evaluating, and steering the learners, both individually and in distributed teams. Instructors in expert-led distributed learning virtual environments serve as facilitators and course managers. They can enhance the critical thinking and creativity of the learners by what if questions. 
The individual learning environment engages the learner and provides a high degree of tailored interaction. Such an interaction can be enhanced by using virtual instructors (intelligent software agents) assigned by the human instructors. It can be used to study physical phenomena that can be coupled with engineering processes, using advanced visualization, multimedia, and multi-sensory immersive facilities. The individual learning environment can serve to carry out virtual experiments - computer simulation of physical experiments. Collaborative learning environments teach teamwork and group problem solving. Instructors and learners can be geographically dispersed. Eventually, they can be brought together through immersive telepresence facilities to share their experiences in highly heterogeneous environments involving different computing platforms, software, and other facilities, and they will be able to work together on designing complex engineering systems.

In HRLN, extensive use is made of intelligent agents developed by the technology providers. Such an agent can be a virtual instructor or a peer learning-companion. For virtual instructor, agent is both an expert and a motivator, rather than being a mentor, because this is the most effective pedagogical role [Ref. 3]. For a peer or a learning companion, the agent plays many roles such as initiator, suggester ("Let's do it this way"), supporter (“That was great!") or summarizer ("Here is what we have done so far") [Ref. 4].

A step towards the implementation of HRLN is the development of an adaptive web portal (Figure 1), which integrates the three learning environments with a knowledge repository, a learning management system and a customized collaboration infrastructure. It also provides advanced multimodal interfaces and a number of additional facilities for automating all routine tasks and satisfying the user preferences.

Each course within the network is divided into self-contained learning modules. These selfcontained learning modules provide flexibility and interdisciplinary curricula. Advanced instructional technology, modeling, simulation and visualization facilities and authoring tools are used in the development of the modules. The learning modules are then packaged into disciplinary and interdisciplinary courses and training programs to satisfy the needs of diverse groups.

In the individual learning environment, the learner navigates through the large database of course modules with the help of concept maps. Concept maps are tools for organizing and representing knowledge. They include concepts and relationships between concepts or propositions. Typically, concepts are indicated by words enclosed in boxes and the relationships by words over lines connecting the concept boxes; hence the name "concept map." Definitions of a concept and a proposition are given by Novak [Ref. 5] as follows. A concept is a perceived regularity in events or objects, or records of events or objects, designated by a label.

Propositions are statements about some object or event in the universe, either naturally occurring or constructed. Propositions contain two or more concepts connected with other words to form a meaningful statement. The concept map presented in Figure 2 will be explained in the next section. 


\section{On Course Content}

The design optimization module is developed and presented here as an example which is a part of the "flow sensing and control" course. The modules are placed and linked in a way that they can be reached, only if and when needed by the learners, through the concept map created for the overarching objective of flow sensing and control (Figure 2). As shown on the concept map, the design optimization is one of four fundamental levels of the flow sensing and control module.

The knowledge of design optimization should allow the learner to work on improving the design of a controller, actuator or sensor. The present design optimization methodology employs computational fluid dynamics to evaluate the performance of a given design. Computational Fluid Dynamics (CFD) can be useful beyond merely simulating a fluid flow, and be utilized for the purpose of design and optimization in order to cut down the cycle time for a new product [Ref. 6]. Design optimization is a systematic methodology to create or improve a design. It may produce the "best" design or just a "better" design. Design optimization can be a conduit to understand the design process and the effects of physical phenomena associated with evolving shapes or designs [Ref. 6]. However, cutting down the cycle time for a new product may be a prohibitive proposition for the needed computational and human resources if, as often is the case, a large matrix of candidate designs or design variables are involved. Improving the accuracy and efficiency of this process can reduce its cost and increase its effectiveness. There are other compelling and motivating factors that push and pull design optimization, such as, the needs for a fast response to the market changes.

With all of this as impetus, the researchers have been developing new design methods, varying from inverse methods to numerical shape optimization methods. Some of the objectives that such efforts try to accomplish are:

(i) Automated design optimization with minimal need for designer-in-loop in a given try.

(ii) Reduce the need for the design expertise and the prerequisite database.

(iii) Improve accuracy, efficiency and practicality.

(iv) Information on the most influencing parameters, which leads to a reduced CFD analysis matrix, requires sensitivities of objectives and constraints with respect to design variables.

(v) The ability to design with a variety of aerodynamic and geometric constraints and geometric flexibility, i.e. the type and the number of design variables and efficient parameterization.

The next required step is the education and the training of the graduate engineering students, practicing engineers and the researchers so that they can use these multidisciplinary tools routinely and effectively. However, in the present study, this is contemplated neither for the traditional in-class pedagogy nor using the traditional synchronous or asynchronous methods. Rather, the concept of a hierarchical research and learning network (HRLN) is being explored in a NASA initiated and funded university consortium led by the Old Dominion University's Center for Advanced Engineering Environments [Ref. 1]. 


\section{Description of Design Optimization Learning Module}

The present HRLN module is developed with the help of an "authoring tool" distributed by a technology provider [Ref. 7]. Using this tool, one can create, for example, web-based tutorials and sophisticated simulations incorporating audio and video for "e-learning." In the learning module, the intelligent agents are intended to look and sound like a human being. Research on intelligent agents suggests that more an agent looks like a human being more effective it can be [Ref. 3]. While an agent "speaks," a learner can also see the spoken output in a word balloon. It is possible to change the speaking speed of agent. These features of the agent are provided through a user menu button. Using the top menu button, a learner is provided with module's table of contents, with hyperlinks to each content item. Hence, a learner can easily navigate through the module. Based on the learners need for information, one can navigate through the entire module using the concept map (Figure 2), picking and choosing paths to skip and those to be followed. Forward and backward buttons are provided for this purpose. For the remainder of this section, a series of sample screens will be presented. The module begins with the links to its five chapters (Figure 3):

1. Basics of Optimization,

2. Introduction,

3. Theory and Formulation,

4. Examples,

5. References.

When the Basics of Optimization chapter is selected, the learner will be asked whether the basic mathematics pertinent to optimization is needed (Figure 4). Here the agent plays the role of a coordinator. In this chapter, math topics that are used most often in optimization are available, such as, linear independence, quadratic forms, positive definiteness, sets, functions, continuity, gradient, Hessian and Taylor series (Figure 5). As this is an environment for a selfpaced learning, the learner can choose to repeat any topic as needed. Using the $\AA$ button a learner can repeat any each page as many times as needed.

A chapter on the basics of optimization is also provided. In this chapter, fundamental concepts of optimization, such as, defining an objective function, design variables, constraints, are provided to the learner. Following the fundamental concepts of optimization, a section is provided on how to perform one-dimensional unconstrained minimization or general unconstrained minimization, or constrained minimization. Some concepts given in this section are the definitions of optimum design point, necessity conditions, and finding the minimum (Figure 6). Topics, such as, when and why there is a need for design optimization, different approaches to design, are provided in the Introduction section (Figures 7-8). The learner should be able to decide which approach is best suited for the need at hand based on this section.

The Theory and Formulation section starts with a flowchart of the choice of design approach for this module, that is, automated design optimization (Figure 9). Different formulations for design optimization and sensitivity analysis are also presented as a section in this chapter. In this

"Proceedings of the 2004 American Society for Engineering Education Annual Conference \& Exposition Copyright (C) 2004, American Society for Engineering Education" 
section, some important steps are highlighted for learner's convenience. First, the formulation of an optimization problem is defined (Figure 10). Then algorithms to obtain the sensitivities are provided (Figures 11-12). As an example, sensitivity equation for steady Euler equations is given in Figure 13. Some additional topics covered in this section are: Gradient based approach, direct numerical optimization, formulations of optimization, direct and adjoint formulations, and sensitivity analysis.

In the next chapter, a learner is provided with a menu of examples. The examples are selected in order relate to the overarching topic of flow sensing and control. These titles are hyperlinked to the pages of these examples. This chapter consists of five sections: Airfoils, nacelles, nozzles, wings and noise barriers. The subtitle for each example contains a brief explanation (Figure 14).

An airfoil shape optimization in supersonic flows is presented in Figures 15-17. To improve the performance of a highly swept supersonic wing, it is desirable to have an automated design method that also includes a higher fidelity to the flow physics. The present investigations was aimed at achieving the following objectives using only two dimensional simulations for the sake of cost-effectiveness: 1) Perform a supersonic wing section optimization considering the viscous effects of the flow and investigate possible nontraditional optimum profiles; 2) Study an automated optimization leading to designs favoring the leading-edge thrust; 3) Suggest initial designs and optimization problem formulations for future, detailed, three dimensional, viscous, supersonic wing designs; 4) Establish the present design method's capability in handling diverse test cases for such problems. This example is formulated to obtain the optimum airfoil shape for maximum lift-to-drag ratio (cruise efficiency), subject to a maximum allowable drag while attaining a minimum lift. It was set up for a NACA 0004 airfoil with flow past at Mach 2.4, angle-of-attack of 4.5-deg, and a Reynolds number of 2 million [Ref 8].

As a second example, an internal-external nozzle configuration is considered. The problem is defined and constraints are given in (Figure 18). An aerodynamic optimization method can be improved considering the following two advancements. Firstly, nonlinear fluid dynamic phenomena including flow discontinuities are better predicted by an improved flow prediction method, which uses third order accurate discretization of the Euler equation. Using this method the flow field of the original shape, which generates shocks and other large gradients, is predicted based on the shock-free flow field of the original shape and without solving the flow field equations. Secondly, every surface grid point is used as a design variable, which virtually eliminates all geometric restrictions on the shape as it is optimized for the specified objective. This improved algorithm is demonstrated by optimizing the ramp shape of an internal external nozzle configuration for maximum thrust, subject to the aerodynamic and geometric constraints. The local contour slopes at each surface grid point are used as design variables. The geometrical constraints are chosen such that axial length of the ramp shape is fixed. Also, in order to maintain an acceptably smooth aerodynamic surface, upper and lower limits of $+5-$ and -5 -deg are imposed on local contour slopes. Starting with totally different initial shapes, virtually the 
same optimum shape is obtained [Ref 9]. A comparison of the initial and optimum ramp shapes (Figure 19) is provided.

\section{Concluding Remarks}

A hierarchical research and learning environment module has been developed for aerodynamic design optimization. This environment is intended to enhance the convenience and the effectiveness of learning significantly. In this environment, learners access the course lectures at their convenience either via the Internet or packaged files. Using this packaged files the learners can get the course whenever and wherever they want. The interaction in this module is enhanced by the optional use of virtual instructors (intelligent software agents) assigned by the human instructors. The environment lends itself very well for individual or group studying and discussions. Another feature that enhances the learning is the learner's ability to navigate through the lecture material so to study only what is deemed as necessary for the individual's level of knowledge. With the help of the concept map and the menu buttons, one can navigate through the entire module.

In the case of a learner who has the needs to refresh the basic mathematics, the module provides the fundamentals of necessary mathematical concepts that are commonly used in optimization. In the introduction menu, the learner is provided the reasons for using design optimization and its overview. The agent helps to retain attention by-asking question in the beginning of each section. The manner, in which the agent lists the reasons for why and when there is a need for design optimization, is intended to motivate and guide the learner.

It is important for a learner to compare and decide which type of design-optimization procedure is most suitable for the need at hand. For this reason, a brief explanation of different methods of design-optimization, including their advantages and disadvantages, are provided. After the theory and formulations, a list of examples is provided. Finally, the module includes a reference section for those who wish detailed explanation of the related topics.

In order to assess the effectiveness, a study needs to be conducted to compare the learning outcomes from this module and those from the same topic covered in the traditional distance learning formats. The effectiveness of this module can potentially be improved by implementing pedagogical enhancements to the course contents. This is left as a future work.

\section{References}

1. Noor, A.K., "New Links for Learning in a Changing Profession," Aerospace America, October 2002, pp.24-35

2. Noor, A.K., "Perspectives on Advanced Learning Technologies and Learning Networks and Future Aerospace Workforce Environments" Advanced Learning Technologies and Learning

"Proceedings of the 2004 American Society for Engineering Education Annual Conference \& Exposition Copyright (C) 2004, American Society for Engineering Education" 
Networks and Their Impact on Future Aerospace Workforce (Ed. A.K. Noor), NASA/CP2003-212437, September 2003.

3. Baylor, A.L., "Systematically Designing Pedagogical Agents: Effects of Image, Animation, and Agent Role on Learner Performance and Motivation," Advanced Learning Technologies and Learning Networks and Their Impact on Future Aerospace Workforce (Ed. A.K. Noor), NASA/CP-2003-212437, September 2003.

4. Goodman, B., "Intelligent Agents for Distance Learning," Advanced Learning Technologies and Learning Networks and Their Impact on Future Aerospace Workforce (Ed. A.K. Noor), NASA/CP-2003-212437, September 2003.

5. Novak, J. D., "Concept Maps and Vee Diagrams: Two metacognitive tools for science and mathematics education," Instructional Science, Vol. 19, 1990, pp. 29-52.

6. Baysal, O., "Aerodynamic Shape Optimization: Methods and Applications," SAE Transactions: Journal of Aerospace, Vol. 108, Section 1, 1999, pp. 794-802.

7. www.macromedia.com/authorware

8. Item, C. C., and Baysal, O., "Wing Section Optimization for Supersonic Viscous Flow," Transactions of ASME: Journal of Fluids Engineering, Vol. 120, 1998, pp. 102-108.

9. Baysal, O., Eleshaky, M. E., and Burgreen, G. W., "Aerodynamic Shape Optimization Using Sensitivity Analysis on Third Order Euler Equations,"(AIAA) Journal of Aircraft, Vol. 30, No. 6, 1993, pp. 953-961

\section{OKTAY BAYSAL}

Professor and Eminent Scholar of Aerospace Engineering at Old Dominion University, where he is also serving as the Interim Dean of the College of Engineering and Technology. He has authored numerous publications in the areas of computational fluid dynamics, design optimization and sensitivity analysis, unsteady aerodynamics, computational aeroacoustics, and micro-flows in micro-electro-mechanical systems. http://www.eng.odu.edu/baysal

\section{MEHTI KOKLU}

Graduate research assistant at Old Dominion University. He received his B.Sc. and M.Sc. in Aeronautical Engineering from Istanbul Technical University in Istanbul, Turkey. His research interests are computational fluid dynamics, design optimization and micro-flows in micro-electro-mechanical systems.

\section{AHMED K. NOOR}

Eminent Scholar and William E. Lobeck Professor of Aerospace Engineering, Old Dominion University. $\mathrm{He}$ is also the Director of the Old Dominion University's Center for Advanced Engineering Environments, funded by NASA in Hampton, Virginia. He is also adjunct Professor of Mechanical and Aerospace Engineering, University of Florida, Gainesville, and the Florida Space Research Institute Distinguished Scholar of Advanced Learning Systems. http://www.aee.odu.edu/index2.php

\footnotetext{
"Proceedings of the 2004 American Society for Engineering Education Annual Conference \& Exposition Copyright (c) 2004, American Society for Engineering Education"
} 


\section{Figures}

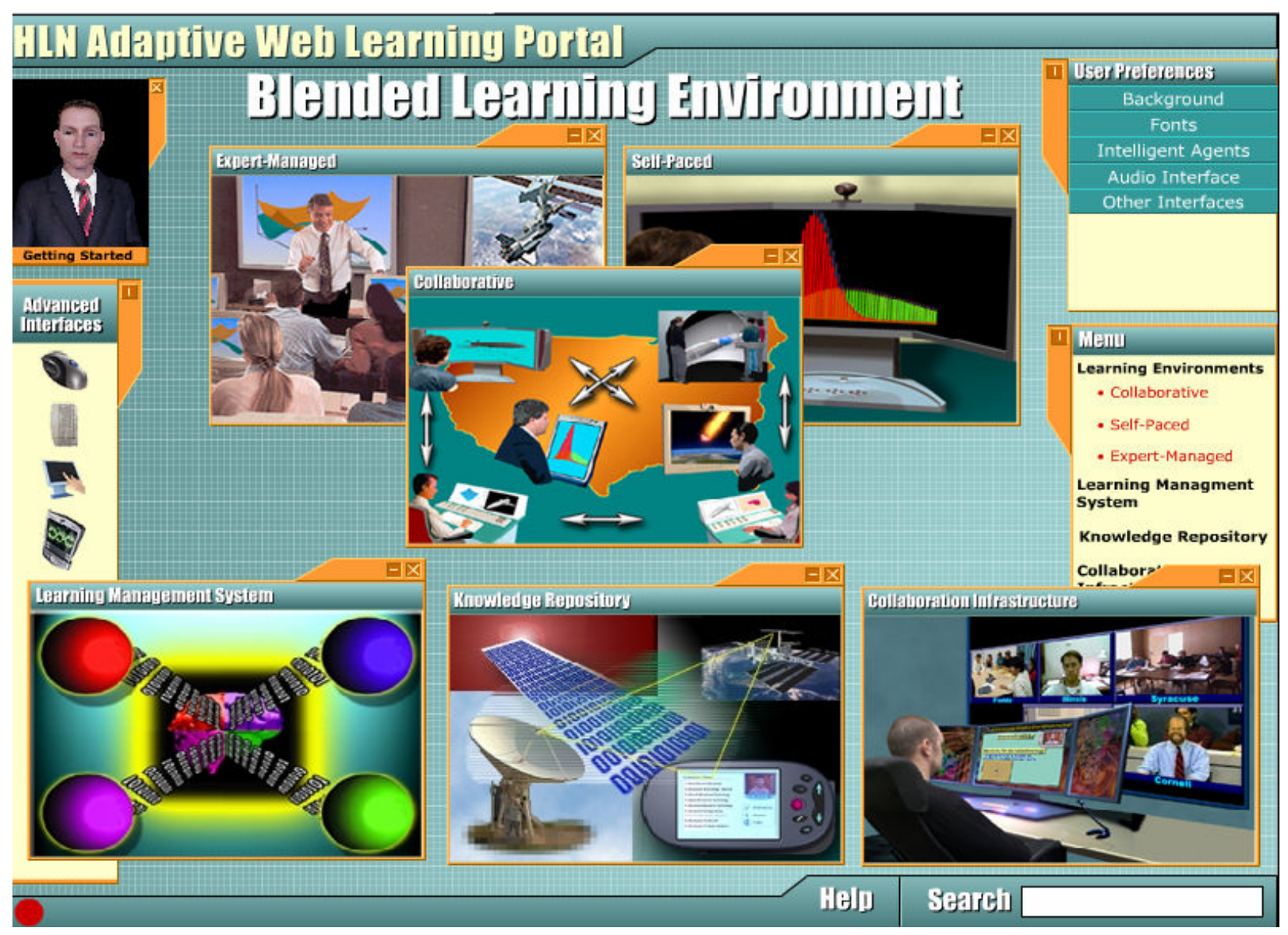

Figure 1. HRLN Adaptive Web Portal

"Proceedings of the 2004 American Society for Engineering Education Annual Conference \& Exposition Copyright (C) 2004, American Society for Engineering Education" 


\section{FLOW SENSING AND CONTROL}

\section{Overview \& Organization}

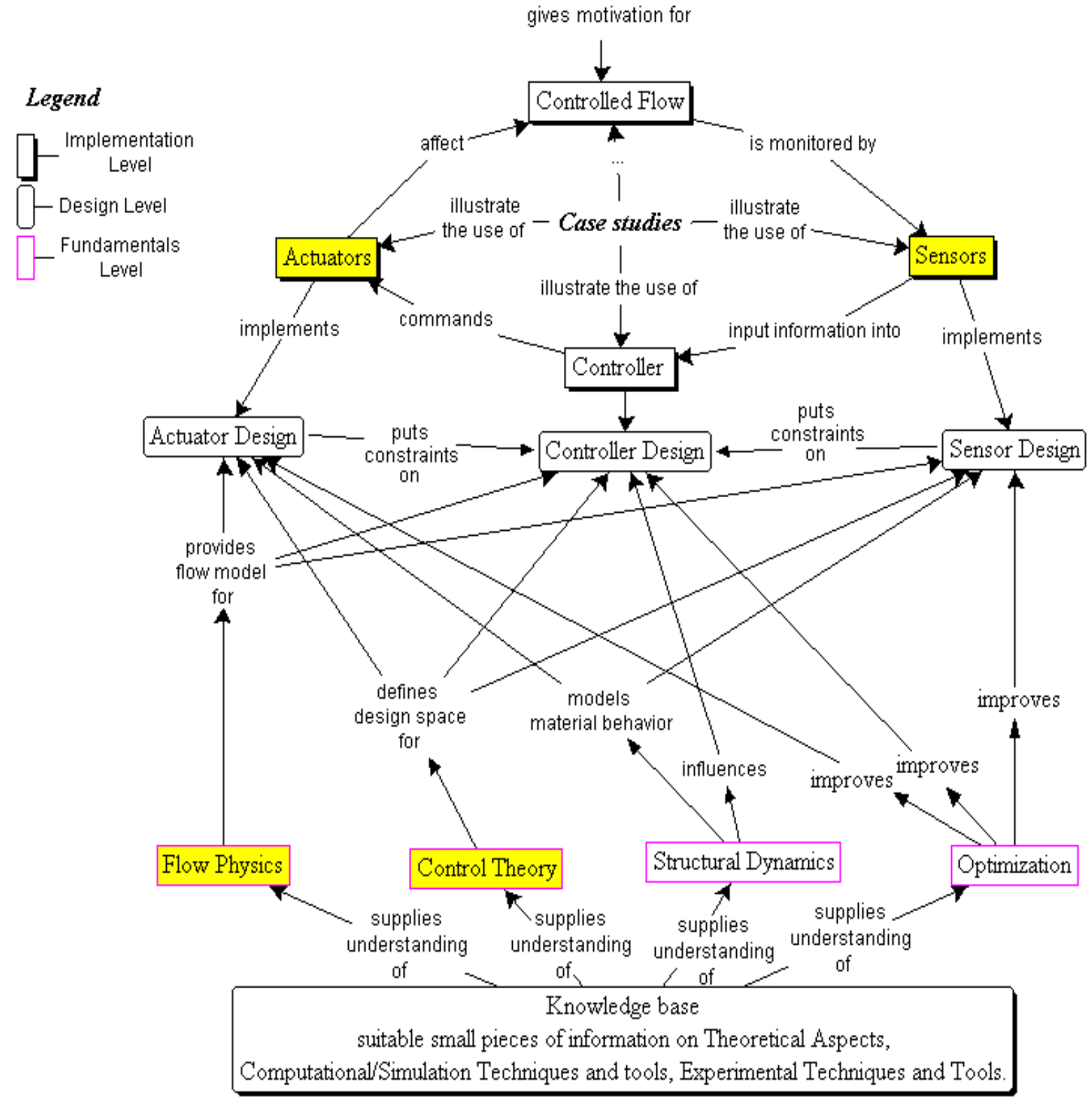

Figure 2. Concept map to learn flow sensing and control (from HRLN Workshop 2003, Hampton, VA).

"Proceedings of the 2004 American Society for Engineering Education Annual Conference \& Exposition Copyright (C) 2004, American Society for Engineering Education" 


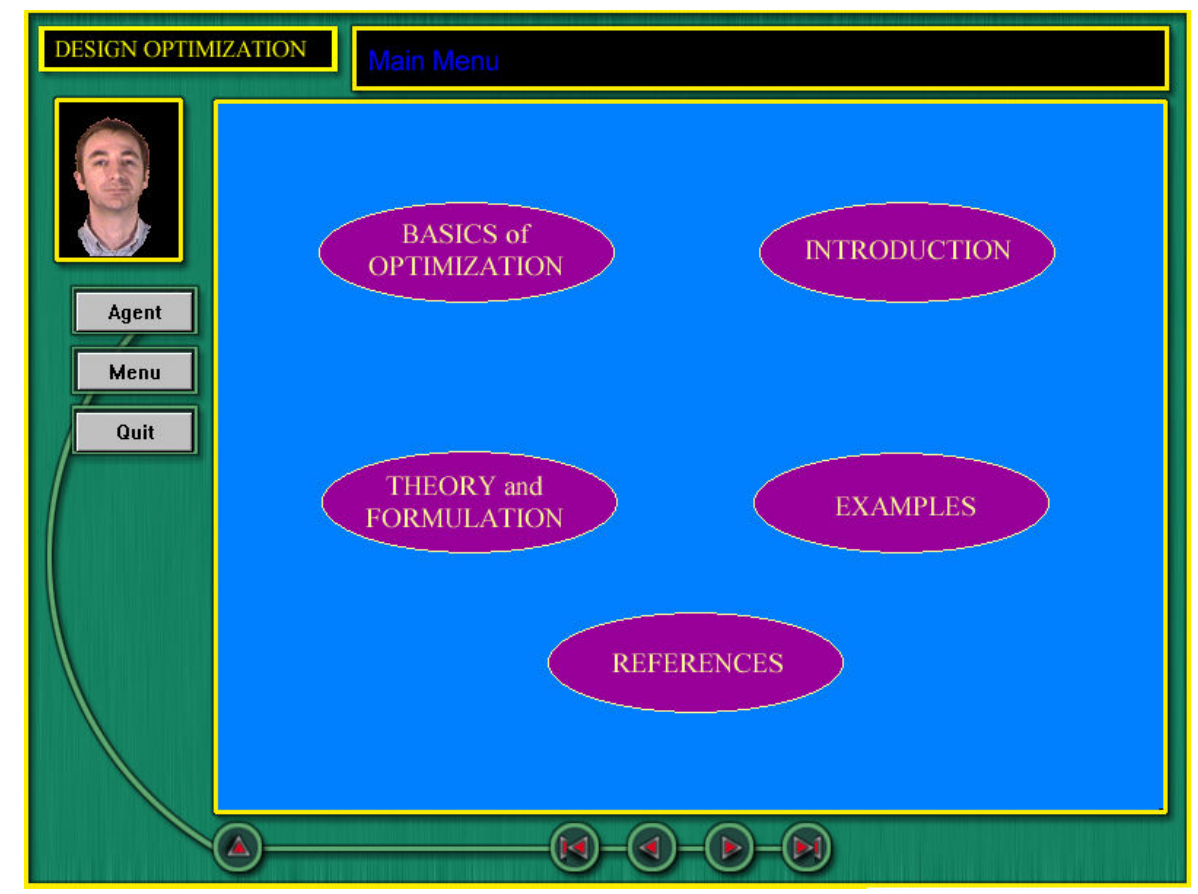

Figure 3. Main menu for the Design Optimization Learning Module.

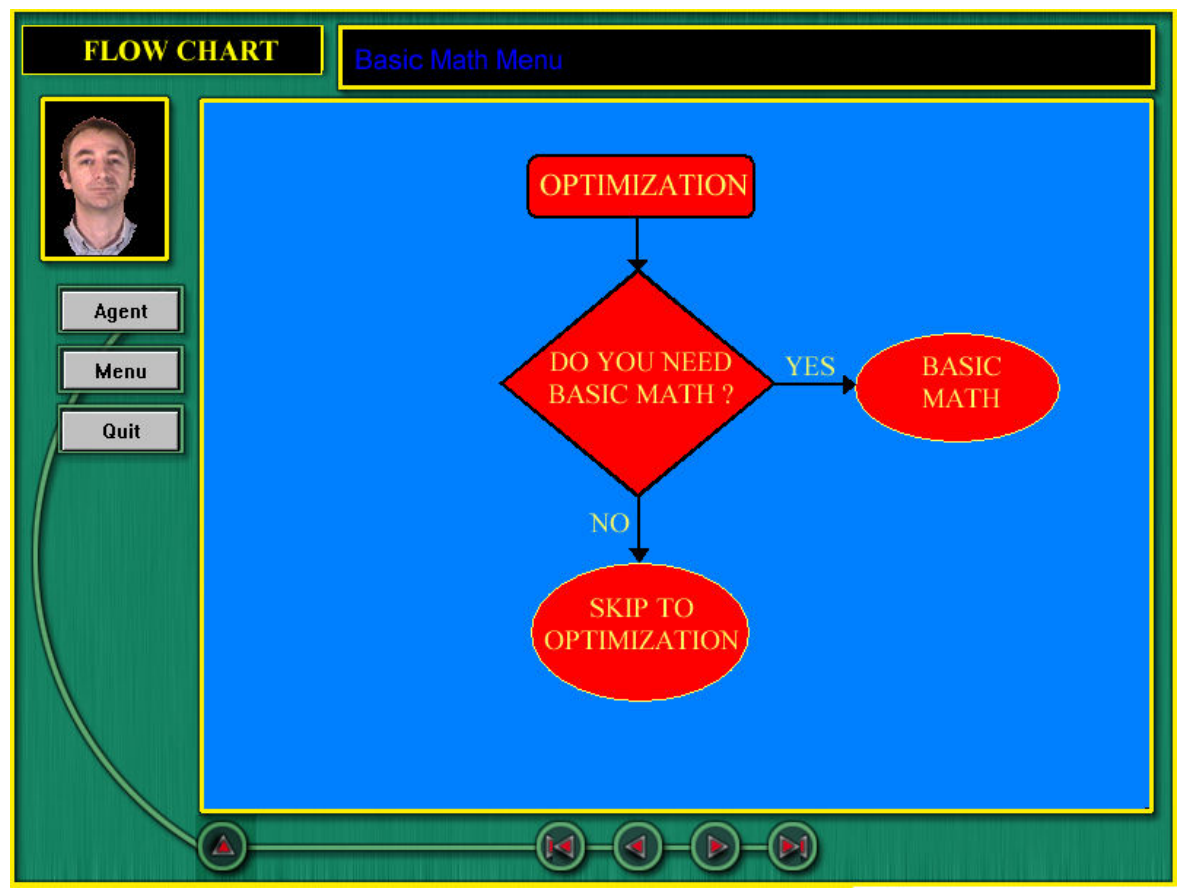

Figure 4. Basic mathematics menu for the Design Optimization Learning Module. 


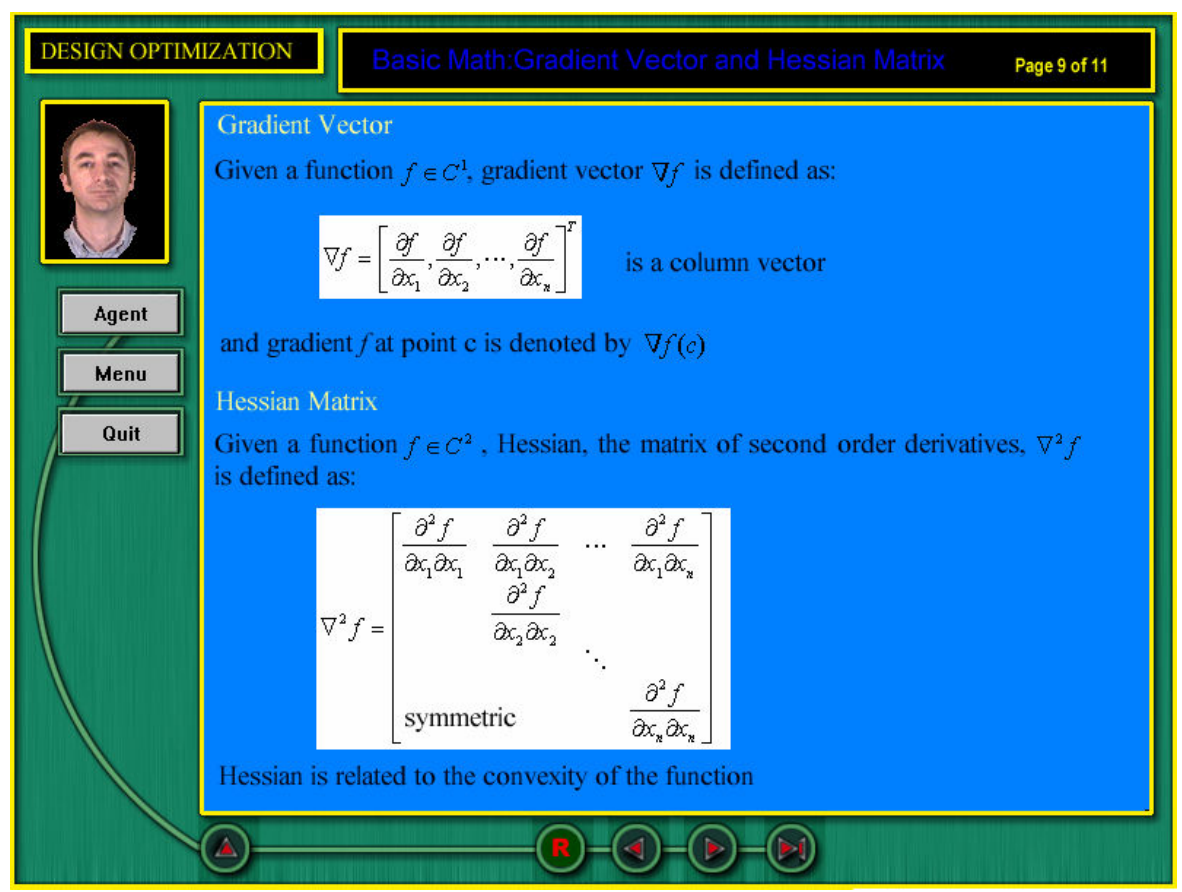

Figure 5. Sample math page: On the gradient vector and the Hessian matrix.

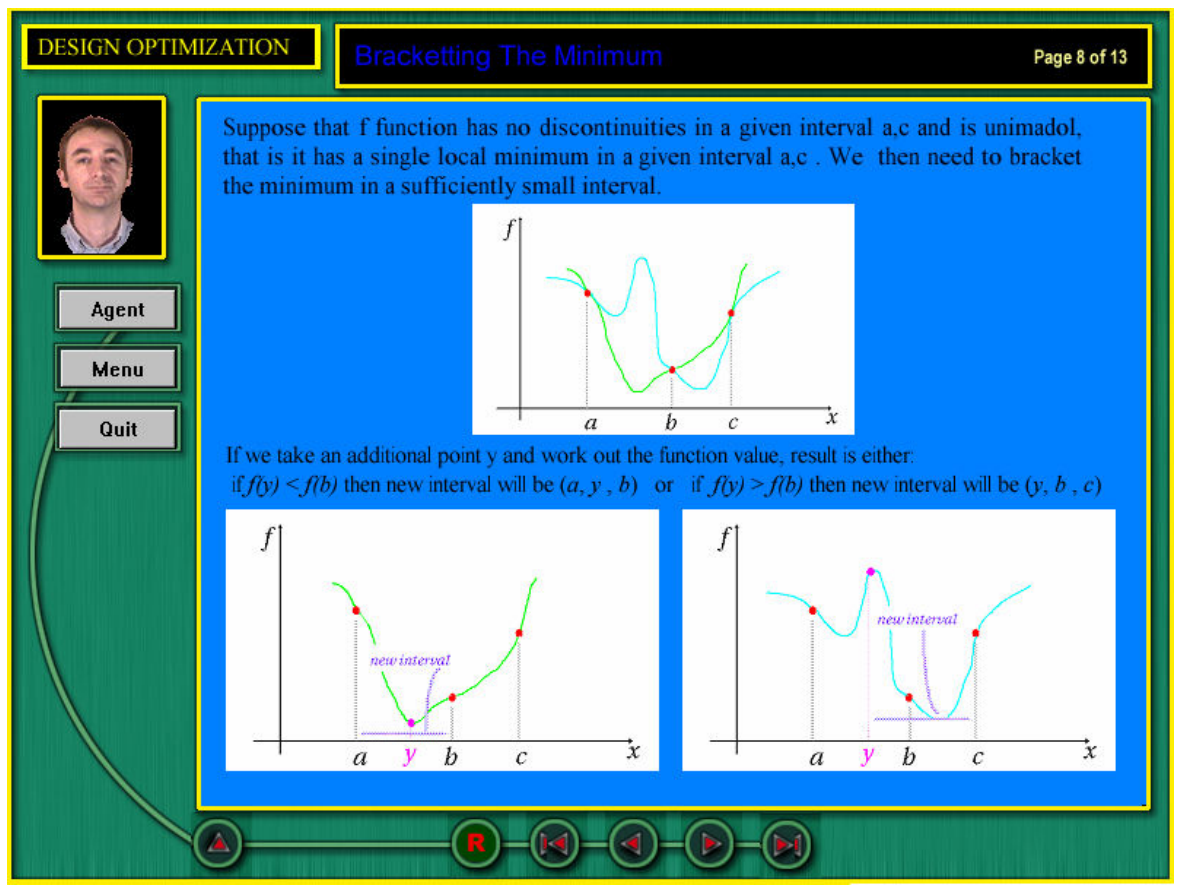

Figure 6. Sample page for optimization basics: Bracketing the minimum.

"Proceedings of the 2004 American Society for Engineering Education Annual Conference \& Exposition Copyright (C) 2004, American Society for Engineering Education" 


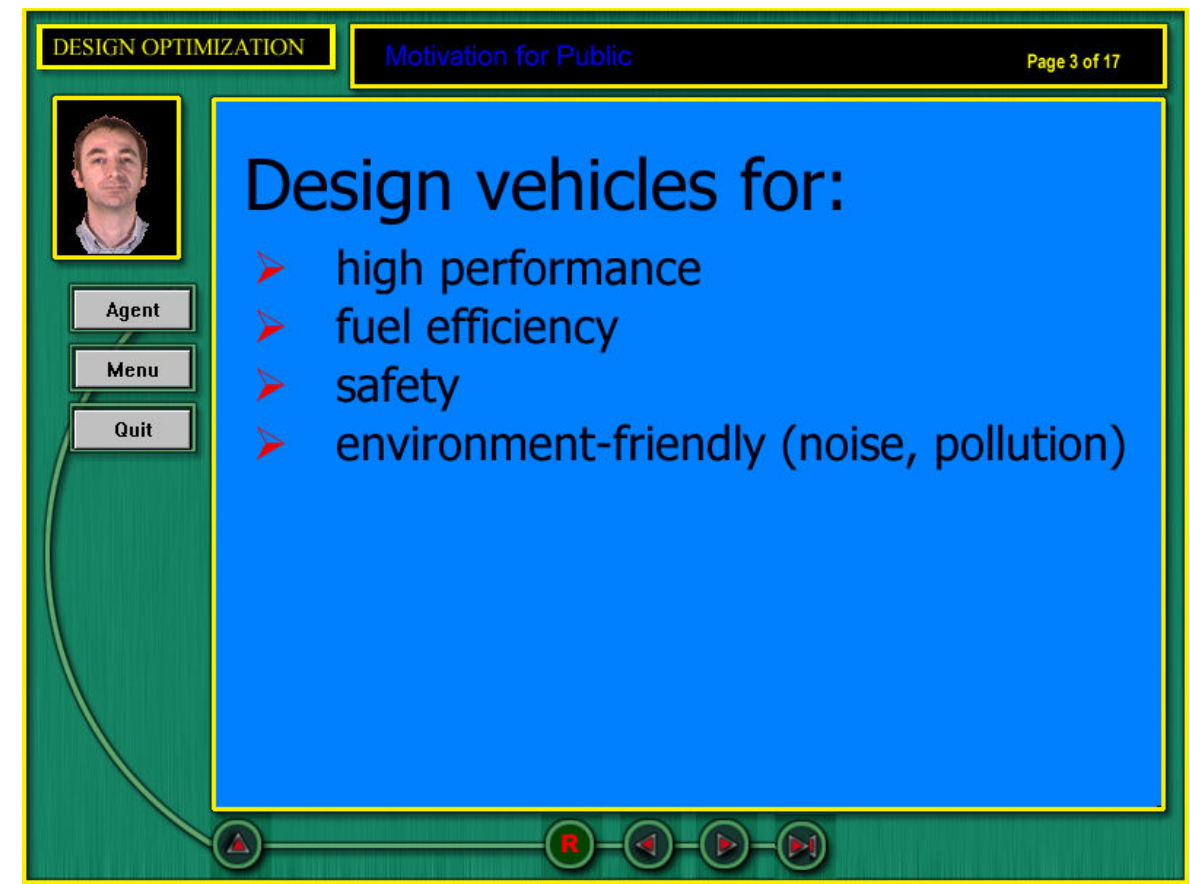

Figure 7. Sample page from the motivation for studying design.

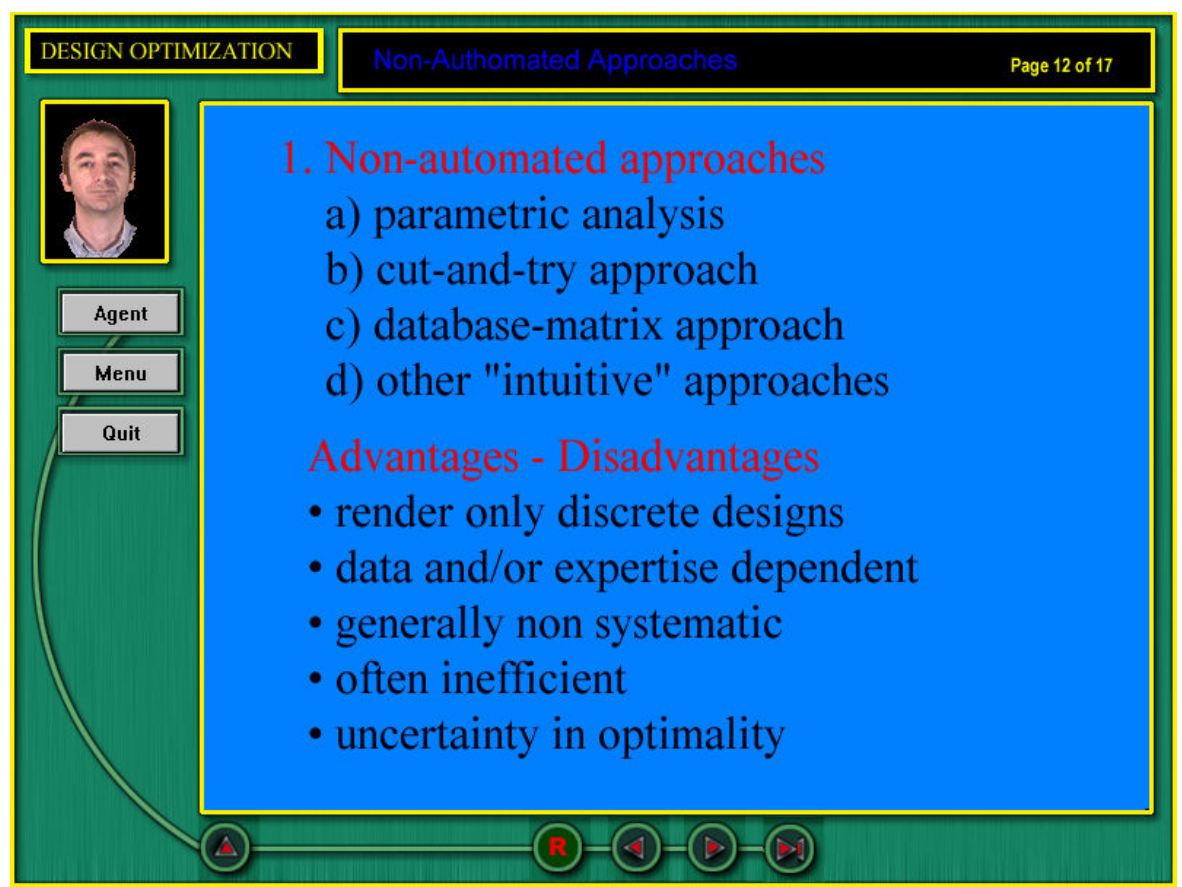

Figure 8. Sample page from the overview of design methods: Non-automated approaches. 


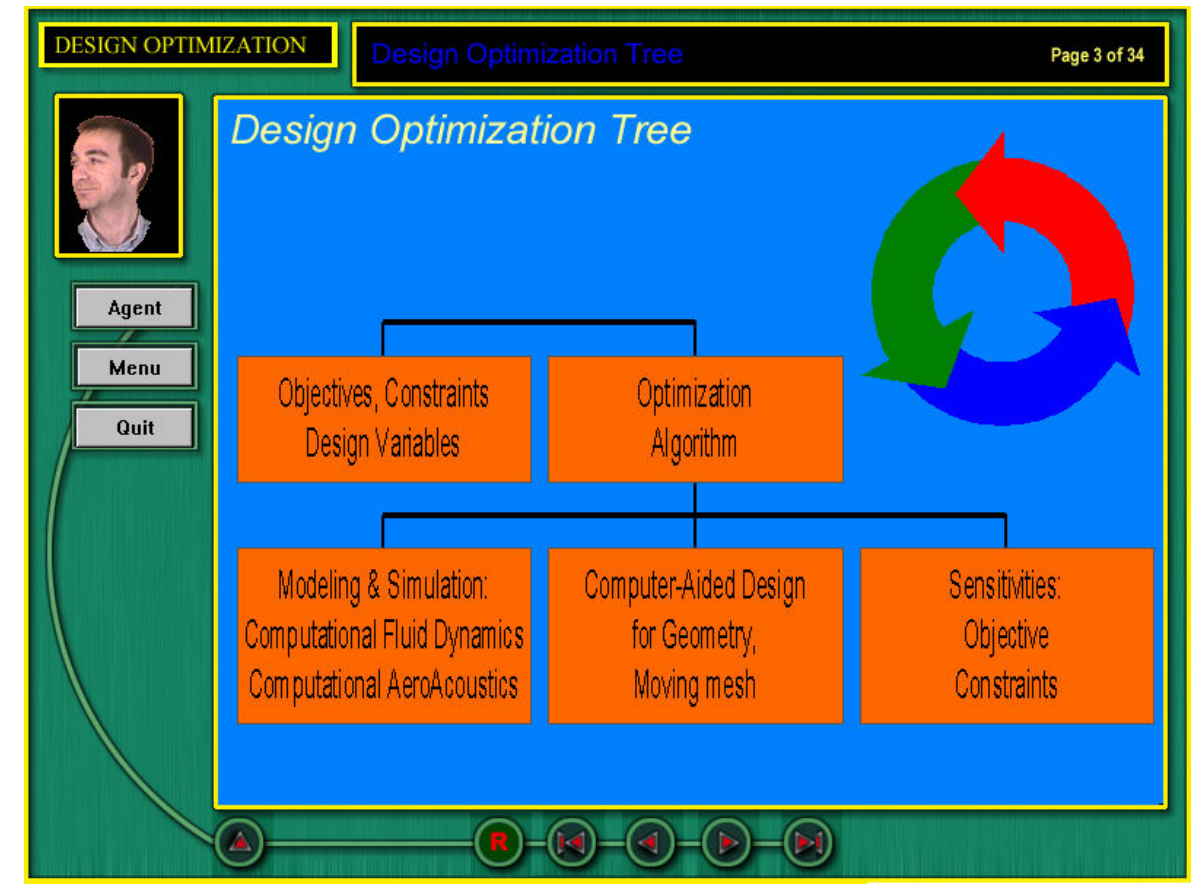

Figure 9. Flowchart of automated design optimization methodology.

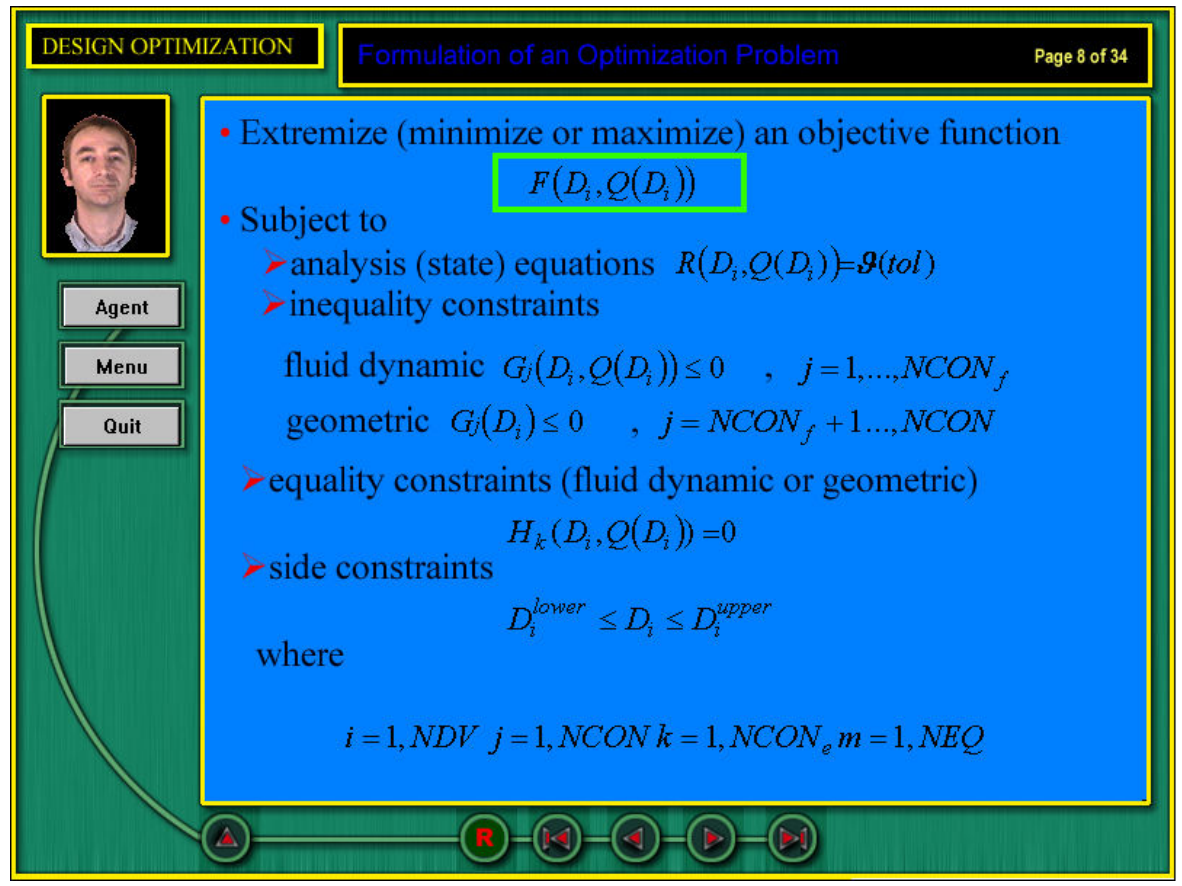

Figure 10. Sample for text highlighting during the lecture: Problem definition page.

"Proceedings of the 2004 American Society for Engineering Education Annual Conference \& Exposition Copyright (C) 2004, American Society for Engineering Education" 


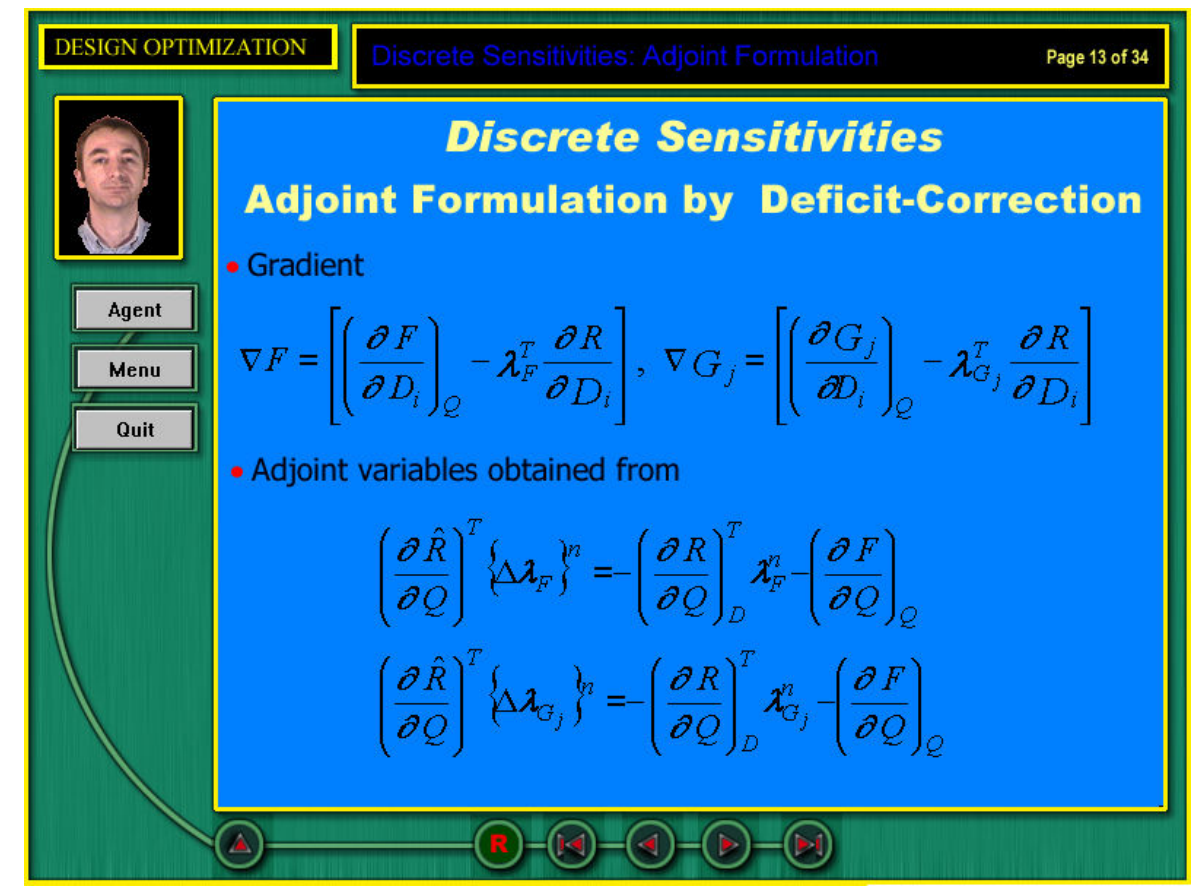

Figure 11. Sample page for discrete sensitivities: Adjoint formulation.

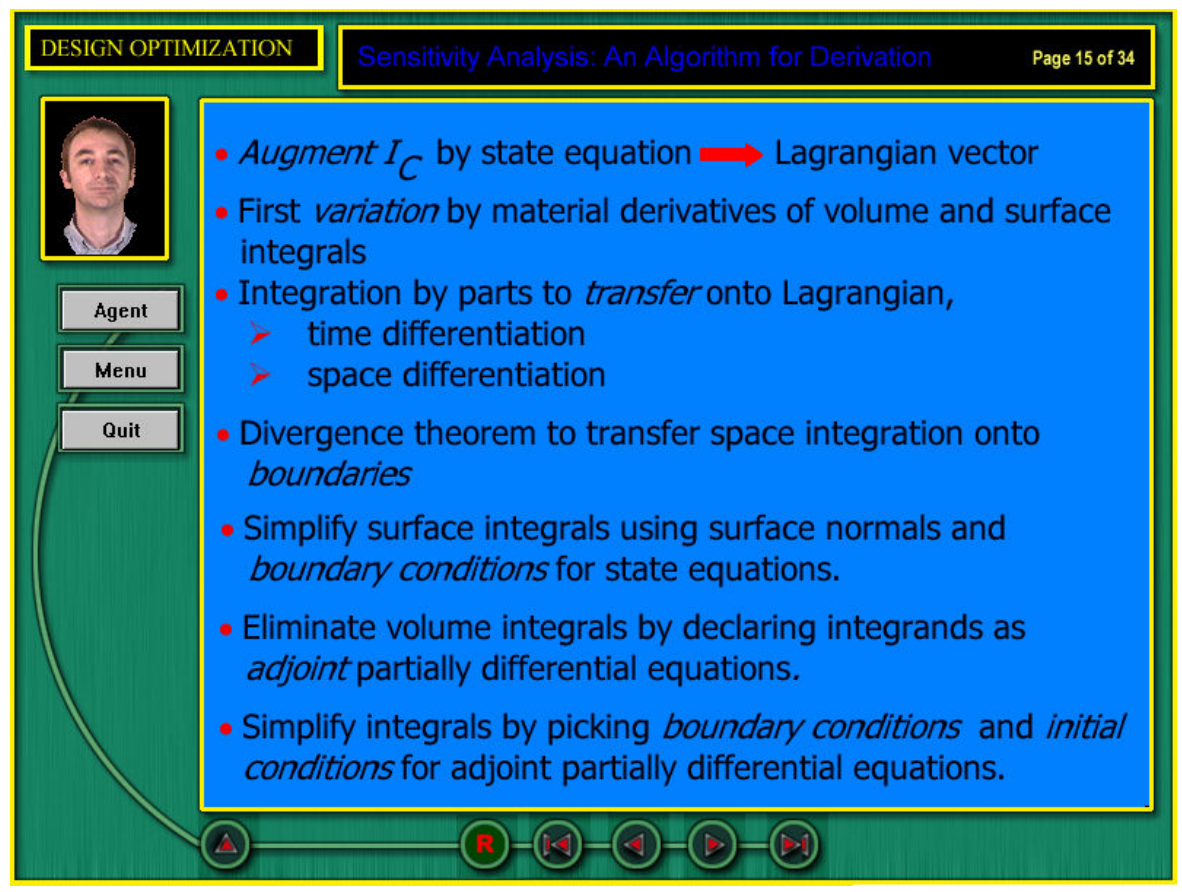

Figure 12. Sample page for continuous sensitivities: Step by step the algorithm for their derivation.

"Proceedings of the 2004 American Society for Engineering Education Annual Conference \& Exposition Copyright (C) 2004, American Society for Engineering Education”"

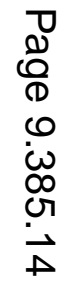




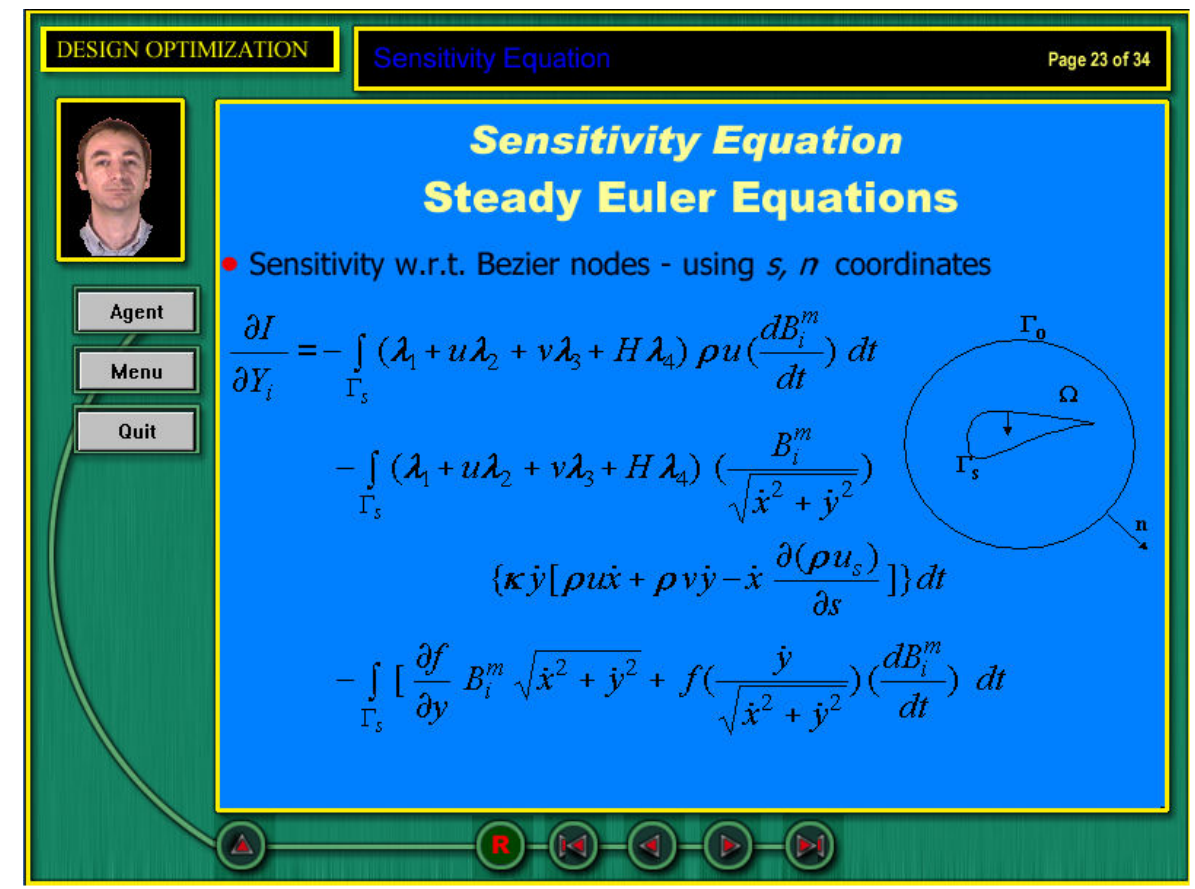

Figure 13. Continuous sensitivity equation for the steady Euler equations.

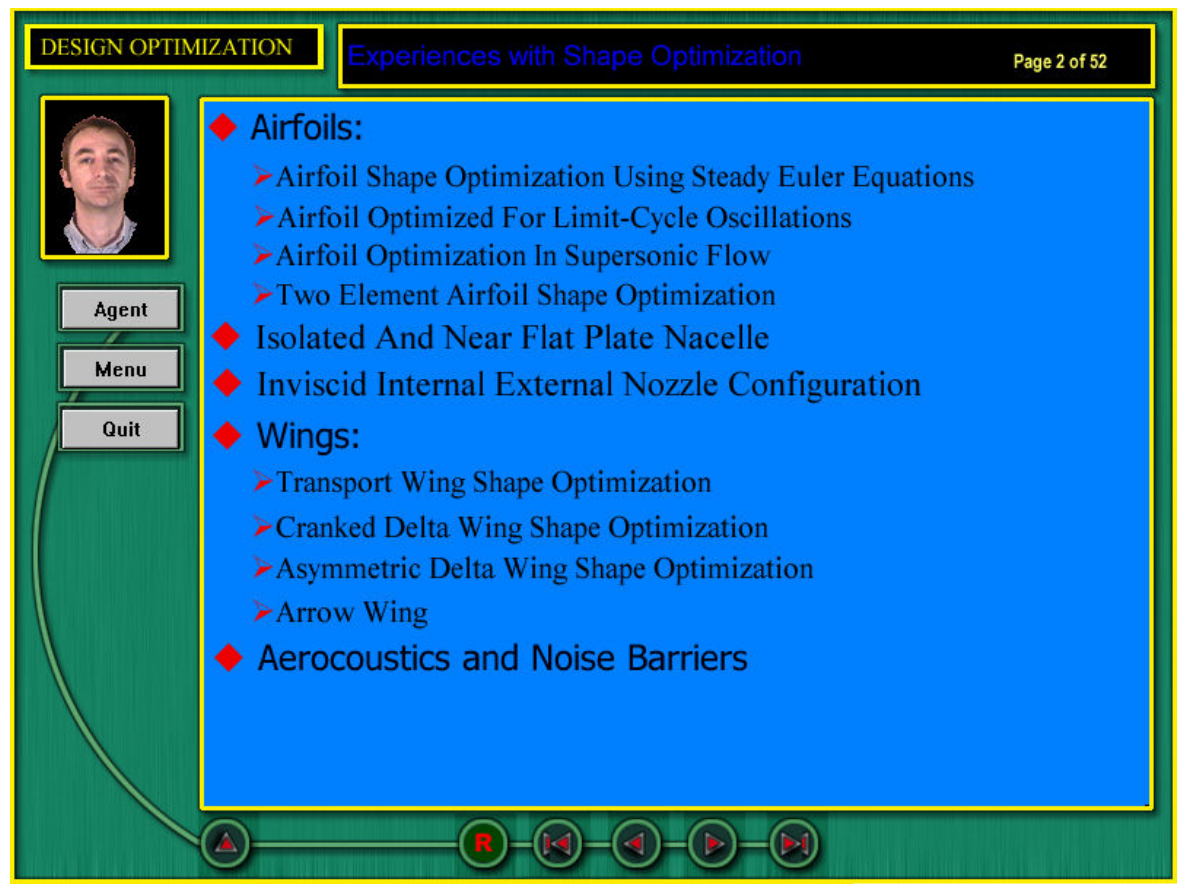

Figure 14. Menu of available examples for shape optimization. 


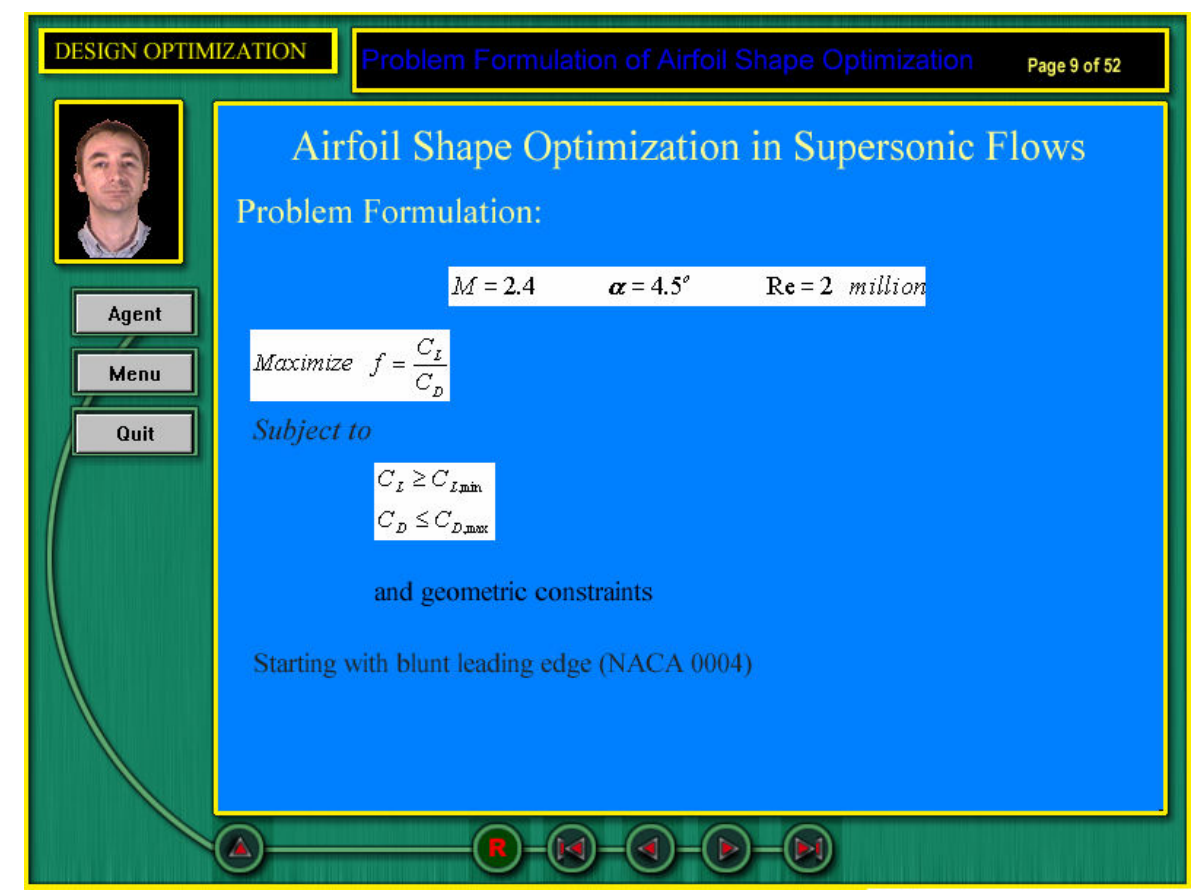

Figure 15. Example 1: Problem formulation of airfoil shape optimization.

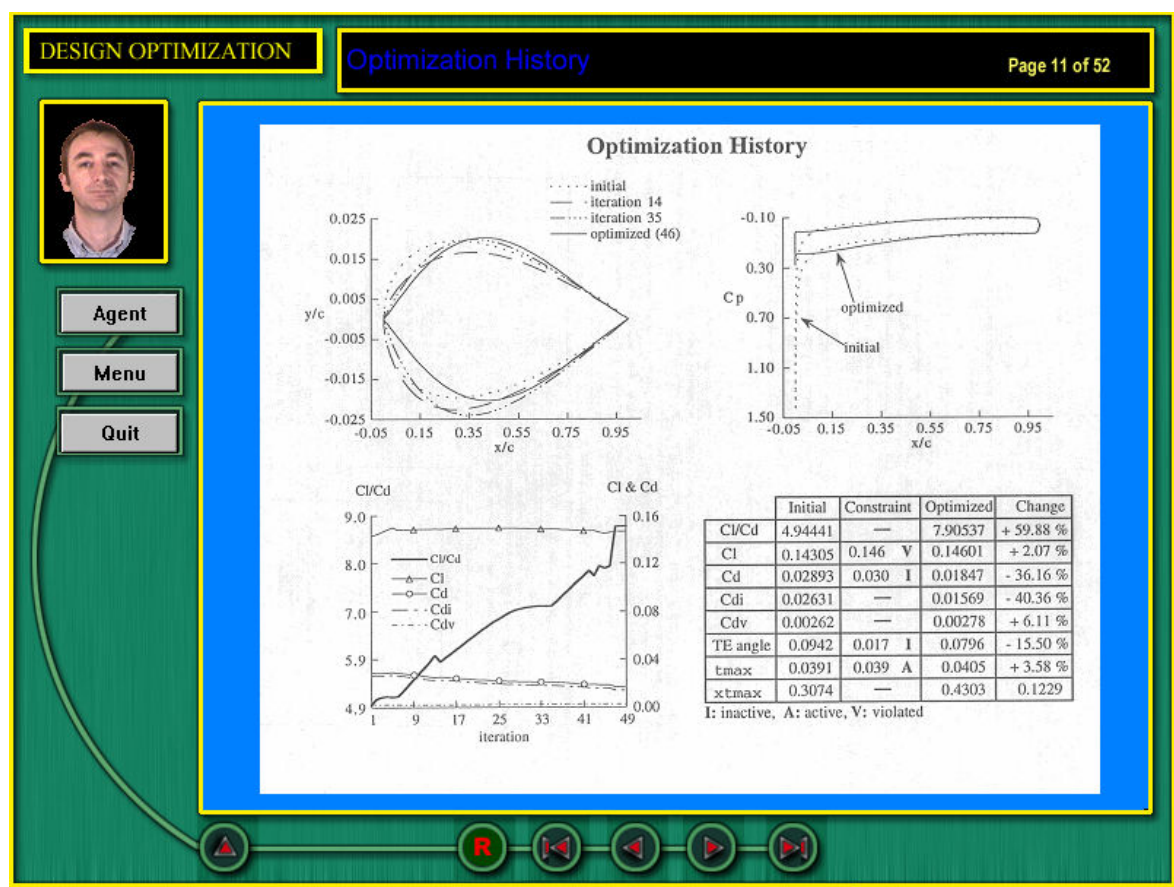

Figure 16. Example 1: Optimization history for airfoil shape optimization. 


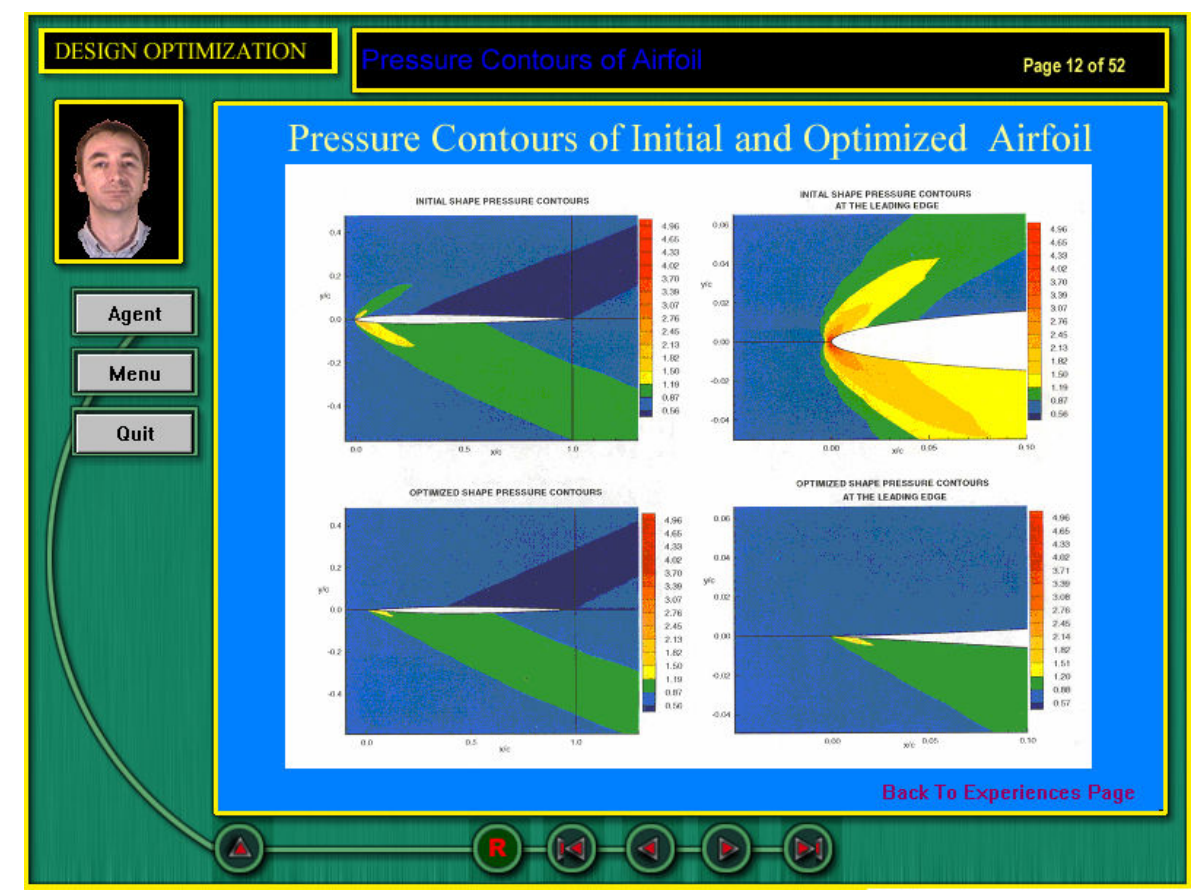

Figure 17. Example 1: Pressure contours of flow past an airfoil before and after optimization.

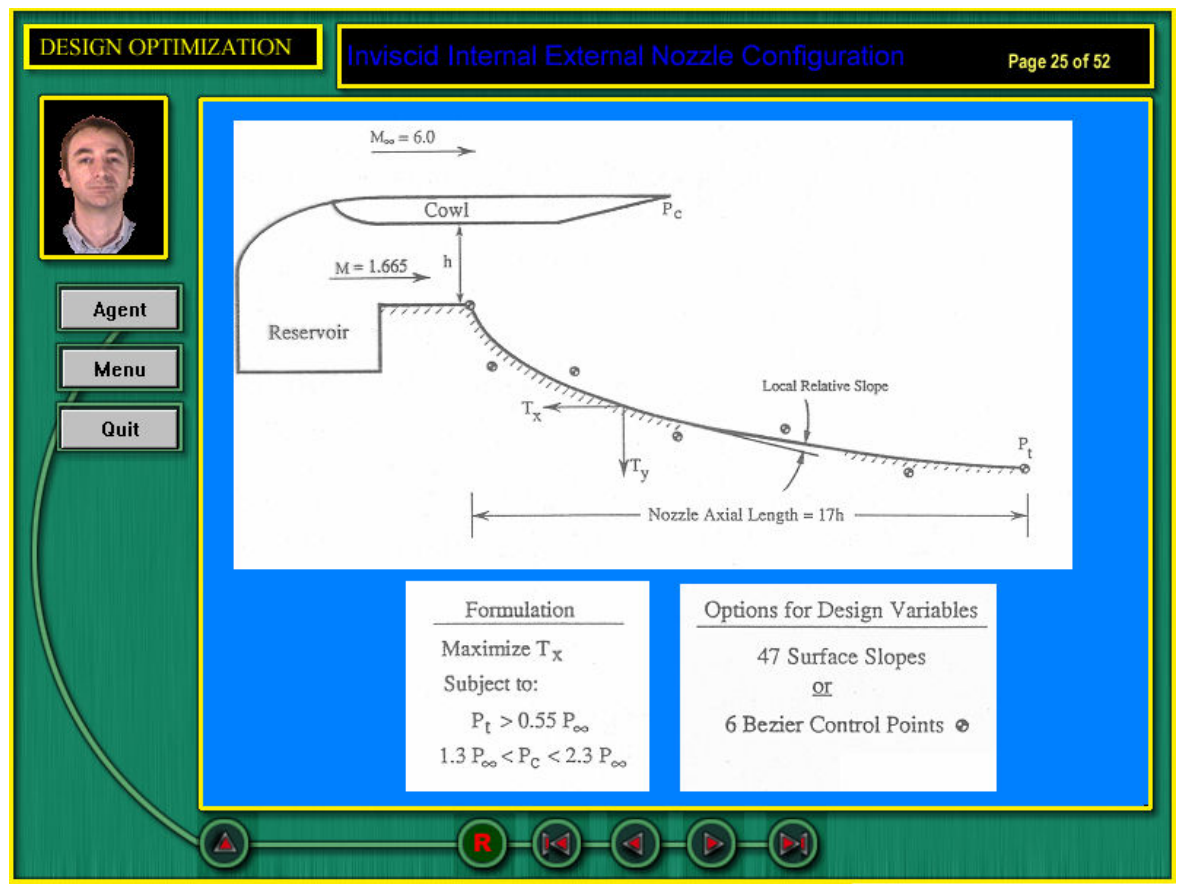

Figure 18. Example 2: Optimization of internal-external nozzle configuration for a hypersonic vehicle. 


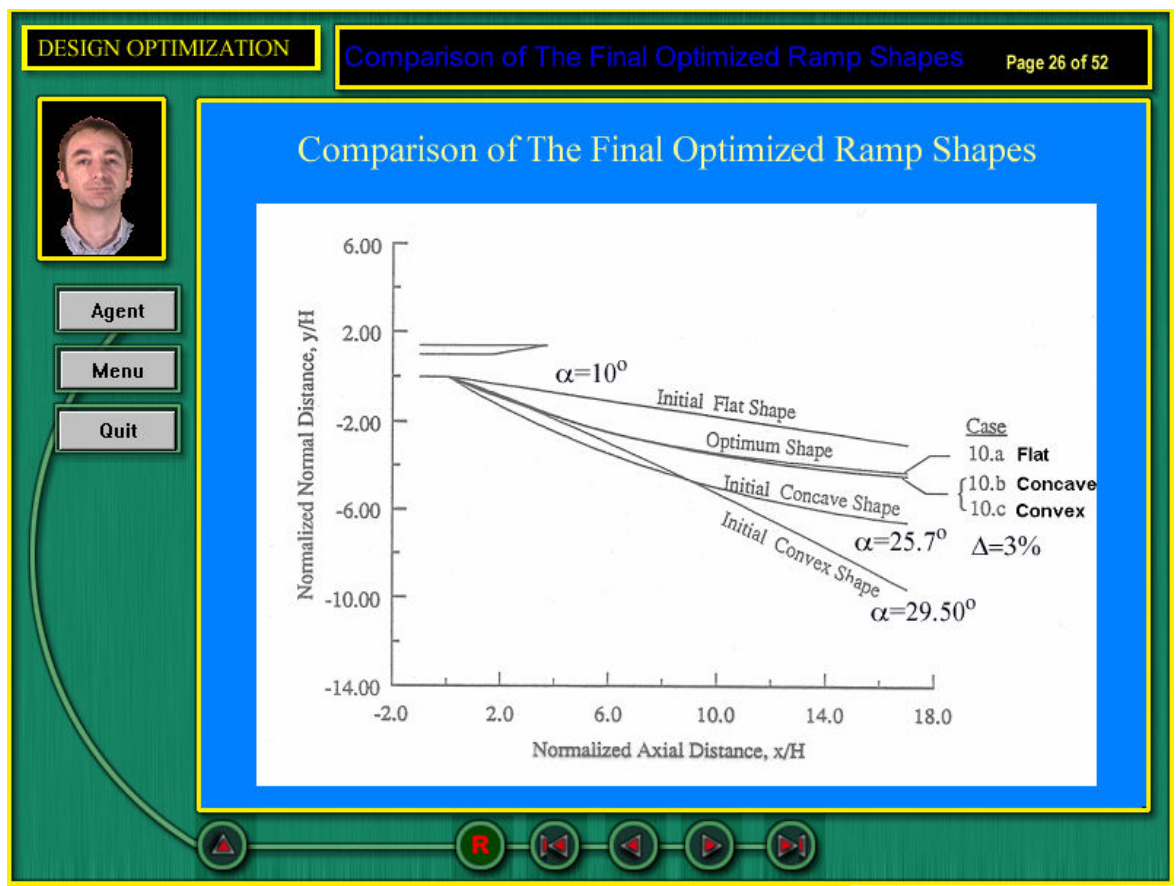

Figure 19. Example 2: Comparison of optimized ramp shapes for the internal-external nozzle. 